base extension is discussed, and the conclusion is reached that it was probably due to lateral refraction caused by a cairn near to which the doubtful ray passed.

The alterations which this check triangulation would produce in the sides which were revised were from I in 39,000 to I in 94,000 , and the angular corrections from $0.989^{\prime \prime}$ to $1 \cdot 066^{\prime \prime}$.

Captain H. Winterbotham proceeds to discuss the accord between the bases which have been measured at Salisbury Plain, Lough Foyle, Lossiemouth, and the French base at Paris, calculated through the side Cassel les Harlettes, and investigates the accuracy of the triangulation as shown thereby. Four other bases which were measured with Ramsden's steel chains at the beginning of the eighteenth century are also compared, though they were not used in the reduction of the triangulation, and are in good agreement with the other results.

The general result is to show that the alteration which would probably be caused by the re-measurement of an arc in the Lnited Kingdom would be small, and that the agreement between the calculated and computed lengths of the Salisbury Plain and Lough Foyle bases was not accidental, since the other bases here used indicate an accuracy of triangulation of the same order.

H. G. L.

\section{THE BONAPARTE FUND.}

THE Committee appointed by the Paris Academy of Sciences to allocate the amount placed at its disposal by Prince Bonaparte, makes the following proposals for grants during igI4.

2000 francs to Dr. Pierre Breteau, for the continuation of his researches on the use of palladium in analysis and organic chemistry; 2000 francs to M. Chatton, to enable him to continue his researches on the parasite Peridinians; 3000 francs to Dr. Fr. Croze, for the purchase of a concave diffraction grating and a $16 \mathrm{~cm}$. objective, to be used in work on the Zeeman phenomena in line and band spectra; 6000 francs to Dr. Hemsalech, for the purchase of a resonance transformer and battery of condensers, to be used in his spectroscopical researches; 2000 francs to P. Lais, for assisting the publication of the photographic star map; 2000 francs to M. Pellegrin, to assist him in pursuing his researches and continuing his publications concerning African fishes; 2000 francs to Dr. Trousset, to assist him in his studies of the minor planets; 2000 francs to M. Vigouroux, to enable him to continue his researches on silicon and its different varieties; 3000 francs to M. Ailuaud, to assist the publication (with Dr. R. Jeannel) of the scientific results of three expeditions to eastern and central Africa; 9000 francs divided equally between M.M. Pitart, de Gironcourt, and Lecointre, members of the Morocco expedition, for scientific study, organised by the Société de Géographie; 2000 francs to M. Vasseur, for the continuation of his geological excavations in a fossil bearing stratum in Lot-etGaronne; 3500 francs to Dr. Mauguin, for the cuntinuation of his work on liquid crystals and the remarkable phenomena presented by these bodies when placed in a magnetic freld; 2000 francs to Dr. Anthony, to defray the cost of his researches on the determinism of morphological characters and the action of primary factors during evolution; 4000 francs to M. Andoyer, to assist the publication of his new set of trigonometrical tables; 4000 francs to $M$. Bénard, to enable him to continue, on a larger scale, his researches on experimental hvdrodynamics; 2000 francs to Dr. Chatuvenet, for the continuation of his researches on No. 2335 , vor.. 93] zirconium and the complex combinations of that element; 2000 francs to François Franck, for the chronographic study of the development of the embryo, with special examination of the rhythmic function of the heart; 2000 francs to M. Sauvageau, for the pursuit of his studies on the marine algæ.

The Committee recommends these eighteen grants after considering close upon sixty applications for assistance. The amount allocated for the year is 54,500 francs.

\section{NAPIER TERCENTENARY CELEBRATION.}

\section{THE Tercentenary Celebration of the publication} of Napier's Description of the Wonderful Canon of Logarithms opened formally on July 24 under the auspices of the Royal Society of Edinburgh. On Thursday at two o'clock, however, the Committee was able to open to the members of the congress the exhibition of books, calculating machines, mathematical models, relics of Napier, portraits, and other objects of mathematical interest. A fair number of visitors had already arrived in the city, and on the Friday morning the examination room of the University, in which the exhibition was arranged, was a lively scene. The tide-predicting machine under the charge of Mr. Edward Roberts attracted a large amount of attention. Many forms of arithmometers and calculating machines, from the abacus of the East and Napier's "Bones" down to the beautiful instruments of the present day occupied a large part of the hall. Each member received, along with his membership card, the handbook of the exhibition, a large octavo of 340 pages, which contained, not only a descriptive catalogue of what was on exhibition, but also sustained scientific articles on sun-dials, slide rules, integraphs, planimeters, harmonic analysers, nomograms, mathematical models, etc., etc. The articles were contributed mainly by members of the mathematical departments of the Universities of Edinburgh and Glasgow, under the editorship of E. M. Horsburgh.

The opening meeting of the congress was held in the debating hall of the University (Students') Union. The Lord Provost of Edinburgh occupied the chair and introduced Lord Moulton in a brief speech, recalling the main facts of Lord Moulton's mathematical career. Among the audience which filled the fine hall may be mentioned Prof. Andoyer, Prof. Bauschinger, Prof. Cajori, Sir William Bilsland, Dr. Dugald Clerk. Prof. Conway, Dr. Glaisher, Dr. J. P. Gram, Prof. Hill, Prof. Hobson, Prof. Macdonald, Major MacMahon, Dr. Conrad Müller, Sir Alexander Napier, Prof. Nielsen, Prof. d'Ocagne, Prof. Putnam, Berkeley, Cal., Dr. Sheppard, Prof. Stekloff, limiting the list to a few of the representative men from a distance.

Lord Moulton, in his inaugural address, endeavoured to trace the origin and growth of the ideas which finally took form in Napier's Descriptio. Emphasis was laid upon the fact that Napier's first table is a table of logarithms of sines. This seemed to indicate that Napier's intention was to facilitate trigonometrical calculation, although in the Descriptio itself this limitation soon disappears from view. Lord Moulton divided what he judged to be the course of discovery into three stages. The first stage was to create tables which would enable numbers to be multiplied together without actually performing the calculation. For this purpose they must proceed in an order resulting from continued multiplication. The word logarithm seems to preserve the trace of this stage. for there can be little doubt that the word means "the number of the ratio." The second stage 
consisted in passing from the idea of figures to the greometrical representation of the quantity by a line, the repeated operations being perfectly represented by repeatedly cutting off the same fraction of the diminished length. This led Napier to establish the proposition that the logarithms of proportionals are "equally differing." Napier felt fully the importance of this proportion, and he literally revelled in it, showing how it enabled us to find mean proportionals of all kinds, extract roots, calculate powers. In the third stage he boldly applied his principle to continuous motion. Napier was now ready to calculate his table. We give Lord Moulton's own words. "He (Napier) takes the radius and forms from it a geometrical series where the reduction between successive terms is one-hundredth. Say he takes 60 terms of such a series. He knows the logarithms of all these terms and he writes them over against the number. These are widely separated by intervals commencing with 100,000 and diminishing as they proceed. He then takes each of these numbers as the first terms of a geoinetrical series, where the reduction is 5000 out of the million, i.e., one twothousandth. He knows the logarithms of all these numbers. . . Thus he has 1200 numbers fairly well distributed over the field, and of these he knows the logarithms. . . They are to serve as his measuring posts. He therefore takes the table of sines which gives the numbers of which he wished to calculate the logarithms. Taking each sine he sees where it, regarded as a number, comes in the scale. It cannot be far from a measuring post. His method enables him to make a proper allowance in its logarithm for this small difference in fact, and as the logarithm of the measuring post is known the logarithm of the sine is known also. ... I have now given you, as I read it, the line of discovery which led up to Napier's table of logarithms. What deeply impresses me is his tenacity of aim combined with his receptivity of new ideas for attaining it. From first to last it was a table of logarithms of sines that he proposed to make and he did not permit himself to be turned aside from that purpose till it was completed. His concepts evidently widened as he proceeded. . . As soon as the discovery had actually seen the light.... Napier proceeded justifiably to destroy the scaffolding which had been so serviceable in the erection of the building. For example, the plan of taking the radius as the starting point had been of inestimable service in keeping up the continuity of his methods. Before his tables were published he had seen that this was unnecessary and he proclaimed it to be so in the Descriptio. We know that at this time he had seen that it would be better to start from unity as the number the logarithm of which should be zero. . . . A still more remarkable change which he hinself proposed was to follow up the last proposal by fixing unity as the logarithm of I0. That this could be safely done could scarcely have been seen by him until the completion of his work. From the top of the mountain he could see how the climb might be made easier by deviations which to the climbers might well seem to be courting unnecessary difficulty. ... Napier took twenty years to do the work-many of which, probably the greater part of which, were spent in arriving at his method. It would be sad to think that most of this was wasted because the solution came by a lucky chance at the last. In my view all these vears did their share, and I have tried to show how gradual and continuous was his progress. As to the greatness of the achievement it is needless to speak. Logarithms have played well nigh as important a part in mathematical theory as in practical work. We know infinitely more of their nature than Napier or any man of Napicr's age could have done. We have means of calculating them so effective that if all the logarithmic tables in the world were destroyed the replacing them would be the work of a few months. But not all the three centuries that have elapsed have added one iota to the completeness or the scope of the two and only existing systems of logarithms as they were left by the genius of John Napier of Merchiston.'

On the Saturday forenoon the members met in one of the class-rooms of the University to discuss chiefly historic questions relating to the discovery of logarithms. Prof. Hobson was voted to the chair, and Dr. Glaisher opened the discussion by an interesting paper on certain aspects of Napier's work. He pointed out how difficult it is for us with our convenient notations and modern notions, to realise what a supreme intellectual effort it must have been for Napier to do what he did. The problem solved by him would be expressed now-a-days in terms of a simple differential equation. The interesting view which Lord Moulton had brought forward the previous day was worth our consideration, although he himself had never thought of getting behind the beautiful geometrical approach given in the Descriptio.

Prof. Eugene Smith, of New York, read a paper on the law of exponents in the works of the sixteenth century; Prof. Cajori discussed algebra in Napier's day and the alleged prior inventions of logarithms; Lieut. Salih Mourad, of the Turkish navy, gave a short account of the introduction of logarithms into Turkey; and in a brief note from Dr. Vacca, of Rome, it was pointed out that a compound interest rule given in an Italian work of the fifteenth century virtually contained the approximate calculation of the Napierian logarithm of the number 2. Prof. Gibson communicated a careful discussion on the question of Napier's logarithms and the change to Briggs's logarithms. These historic papers raised a good deal of discussion, in which the authors already named, the chairman, and Dr. Conrad Müller took part. Dr. Glaisher agreed very emphatically with Prof. Cajori that it was dangerous to take information second hand. An error carelessly made by one historian was copied by others, and once the error got started it was difficult to get rid of it. It was rot always easy to reach first sources. He had, for example, never seen a copy of Bürgi's antilogarithmic table (as it would be called now) until the day before, in the exhibition, when, through the kindness of the Town Librarian of Dantzig, a copv had been placed on view. The other side of Napier's mathematical work was represented by a paper by Dr. Sommerville on Napier's rules and trigonometrically equivalent polygons, with extensions to non-euclidean space.

On the Friday night the Lord Provost of Edinburgh and the Town Council gave a brilliant reception in the new Usher Hall. On Saturday afternoon the members were received at a garden party by the governors and headmaster of Merchiston Castle School, and were shown the small room at the top of the battlemented tower where Napier used to think and work. On Saturday evening the members and their friends met for social enjoyment in the hall of the University Union.

A memorial service was held in St. Giles's Cathedral on the Sunday at 3.30 p.m. The officiating clergyman was the Rev. Dr. Fisher, of St. Cuthbert's Parish Church, of which church John Napier had been an elder, and in the graveyard of which his body lies buried. A special feature of the service was the presence of the masters and boys of Merchiston Castle School. They numbered 260 , and filled the transept of the Cathedral

(: G. KNotr 